\title{
As recentes transformações sócio-espaciais do litoral de Santa Catarina: o caso da Praia Brava - Itajaí-SC
}

\author{
Aílton dos Santos Júnior* \\ Raquel Maria Fontes do Amaral Pereira
}

\section{Resumo}

Esse artigo busca analisar as transformações sócio-espaciais da Praia Brava - Itajaí/SC, provocadas pela expansão urbana e do turismo, nesta área limítrofe entre os municípios de Itajaí e Balneário Camboriú, nas últimas décadas. O estudo está embasado em propostas teóricas de M. Santos (1982 e 2009) e A. Cholley (1964) que favorecem a identificação de elementos naturais e humanos responsáveis por realidades concretas, definidas espacial e temporalmente. Apóia-se também nas ideias de I. Rangel acerca da evolução da formação social brasileira, expressa na teoria da dualidade (2005), associada ao desenvolvimento cíclico do sistema capitalista. A acelerada urbanização, aliada ao incremento do turismo, atraiu a atenção do capital imobiliário e de políticos locais para este espaço, gerando problemas que vêm aumentando a tensão entre as associações comunitárias e os interesses de grupos privados com influência sobre o poder público.

Palavras-chave: Organização sócio-espacial; Expansão urbana; Desenvolvimento turístico; Especulação imobiliária.

* Doutorando em Administração e Turismo, professor do Curso de Turismo e Hotelaria e Arquitetura e Urbanismo da Universidade do Vale do Itajaí - UNIVALI (ajunior@univali.br).

** Doutora em Geografia, professora do Programa de Pós-Graduação em Administração e Turismo da Universidade do Vale do Itajaí UNIVALI. Pesquisadora do CNPq (raquelfontespereira@gmail.com).

Geosul, Florianópolis, v. 26, n. 51, p 109-128, jan./jun. 2011 
SANTOS JR., A. dos \& PEREIRA, R.M.F.A. As recentes transformações...

Recent socio-spatial changes in the coast of Santa Catarina: the case of Praia Brava - Itajaí-SC

\section{Abstract}

This article intends to examine the socio-spatial changes in Praia Brava - Itajaí / SC, caused by urban sprawl and tourism, in this bordering area between the cities of Itajaí and Balneário Camboriú, in recent decades. The study is based on theoretical proposals by M. Santos (1982 and 2009) and A. Cholley (1964) that favor the identification of natural and humane elements responsible for concrete realities, spatially and temporally defined. It is also supported by the ideas of I. Rangel on the evolution of Brazilian social formation, expressed in the theory of duality (2005), associated with the cyclical development of the capitalist system. The accelerated urbanization, coupled with the increase in tourism, attracted the attention of real estate capital and local politicians to this space, creating problems that are increasing the tension between community associations and the interests of private groups with influence over the government.

Key words: Socio-spatial organization; Urban expansion; Tourism development; Real estate speculation.

\section{Introdução}

O presente trabalho analisa as transformações sócioespaciais ocorridas no bairro da Praia Brava, pertencente ao município de Itajaí/SC, cidade polo da microrregião da Foz do Rio Itajaí-Açu, cuja área tem se caracterizado, nas últimas décadas, por um expressivo dinamismo demográfico e econômico. As mudanças registradas vinculam-se diretamente à evolução da formação sócioespacial catarinense, em especial da área correspondente à foz do rio Itajaí-Açu, inserida no contexto nacional e internacional e decorrem da relação dialética entre os elementos naturais e 
SANTOS JR., A. dos \& PEREIRA, R.M.F.A. As recentes transformações...

humanos, endógenos e exógenos responsáveis por suas características singulares, bem como pela expansão urbana dos municípios situados nessa porção do litoral centro-norte, cuja expansão urbana e demanda turística afetaram também o espaço correspondente ao bairro da Praia Brava.

Para a compreensão e análise da problemática apresentada utilizou-se o referencial teórico proposto por Milton Santos, representado, sobretudo, pelo paradigma de formação sócioespacial (1982), o qual permite a realização de estudos de caráter globalizante que consideram as "múltiplas determinações" responsáveis por uma realidade concreta. A opção por esta perspectiva apóia-se no entendimento de que o espaço é constituído por elementos de diferentes origens e períodos históricos, que sintetizam, de um lado, a evolução da sociedade e explicam, por outro lado, a realidade atual. Tributário da categoria marxista de formação econômica e social, o paradigma de formação sócio-espacial amplia as possibilidades de análise por considerar a relação dialética entre elementos naturais e humanos e por interpretar as relações entre estes elementos em múltiplas escalas (local, regional, nacional e mundial). As transformações ocorridas no mundo, especialmente nas últimas décadas do século passado, intensificaram as trocas, modificando as relações não só econômicas, como também sociais, políticas e culturais, entre as diferentes áreas do globo. Assim sendo, estudar uma região ou uma localidade qualquer exige uma análise mais ampla que leve em conta o funcionamento da economia nacional inserida no contexto mundial e seus reflexos em diferentes regiões do país.

Somente através da apreensão do papel dos vários agentes sócio-econômicos e do nível de interação existente entre eles é que se pode captar o modo como a mesma forma de produzir se manifesta em diferentes regiões, associando a nova dinâmica às condições pré-existentes e às características de cada período histórico. Sendo assim, o estudo parte do entendimento de que o acelerado processo de urbanização e o crescimento do turismo 
SANTOS JR., A. dos \& PEREIRA, R.M.F.A. As recentes transformações...

nessa porção do litoral catarinense não estão dissociados da evolução da formação econômica brasileira.

A especificidade da organização espacial da Praia Brava pode ser interpretada como um sistema de objetos e um sistema de ações em contínua interação, visto que, conforme Santos (2009, p.63), o espaço constitui "um conjunto indissociável, solidário e também contraditório, de sistemas de objetos e sistemas de ação, não considerados isoladamente, mas como um quadro único no qual a história se dá".

A configuração de qualquer território é dada em parte pelos sistemas naturais existentes e pelos acréscimos que os homens impõem a estes sistemas, dando àquele espaço uma existência social que decorre das relações sociais. À medida que a história vai avançando ao longo do tempo, a sua configuração natural é alterada pelas obras dos homens: estradas, casas, plantações, cidades, fábricas, portos, etc. Por isso, é fácil entender que o espaço seja hoje "um sistema de objetos cada vez mais artificiais". (SANTOS, 2009, p.63), lembrando que a interação destes sistemas produz uma dinâmica espacial e que o sistema de objetos traduz-se na configuração geográfica, isto é, representa o cenário no qual se desenrolam as ações. Assim entendida, a organização espacial apresenta-se como o resultado de uma sobreposição, ou melhor, de uma imbricação, de diferentes elementos, sejam eles de ordem natural e/ou social.

Convém destacar ainda que as relações entre os sistemas transcendem as instâncias locais, pois ao mesmo tempo em que a partir do lugar (fração reduzida do espaço) emanam influências sobre o espaço adjacente, a organização dessa instância é também condicionada por relações situadas em escalas mais amplas, às vezes até globais. Esse conjunto de influências deve ser considerado tanto para a análise das transformações sócio-espaciais quanto para a análise das questões ambientais, pois elas resultam do relacionamento da sociedade com o quadro natureza.

Assim, procurou-se descrever as características originais do espaço correspondente ao bairro da Praia Brava, analisando sua 
SANTOS JR., A. dos \& PEREIRA, R.M.F.A. As recentes transformações...

evolução bem como a combinação de elementos de ordem natural e social (CHOLLEY, 1964), responsáveis pela configuração desse espaço, sem menosprezar as determinações endógenas e exógenas que foram, ao longo do tempo, responsáveis por sua singularidade.

A definição do referencial teórico permitiu o entendimento de que o espaço constitui uma realidade objetiva, um produto social em permanente processo de transformação, pois a sociedade atua sobre o espaço o qual, em certa medida, determina as atividades humanas, visto que nenhuma sociedade pode viver fora do espaço (SANTOS, 2009).

Complementando o quadro teórico, a análise apóia-se também nas propostas de Ignácio Rangel, especialmente aquelas relacionadas à evolução da formação social brasileira expressa na teoria da dualidade básica e na periodização da evolução capitalista, ressaltando suas fases de crescimento e retração, com base na teoria dos "ciclos de Kondratieff e de Juglar".

\section{A expansão dos núcleos urbanos na Foz do Rio Itajaí-Açu}

A Praia Brava situa-se entre os municípios de Itajaí e Balneário Camboriú integrantes das primeiras áreas a serem povoadas na faixa litorânea de Santa Catarina, onde a população praticava atividades tradicionais de subsistência mais ligadas à agricultura do que à pesca. As origens do município de Itajaí estão relacionadas à sua localização no litoral norte catarinense e ao seu sítio urbano, assim como à função portuária exercida desde os primórdios da ocupação da orla costeira de Santa Catarina, representada não apenas pelo ir e vir de embarcações, mas também de mercadorias que expressam o movimento visível do próprio porto e as relações sociais correspondentes aos distintos estágios de desenvolvimento da região.

Inserido, pois, no espaço litorâneo catarinense que, como se sabe, foi ocupado tardiamente no contexto colonial brasileiro, $\mathrm{o}$ núcleo urbano de Itajaí desenvolveu-se inicialmente em torno do porto, situado à margem direita do rio Itajaí-Açu, próximo à 
SANTOS JR., A. dos \& PEREIRA, R.M.F.A. As recentes transformações...

confluência com o rio Itajaí-Mirim. As terras foram inicialmente aproveitadas por colonos açorianos que exploraram os terrenos férteis de várzeas e, ao trocarem os excedentes de produção, deram início a um pequeno comércio costeiro limitado pela rígida estrutura colonial.

Foi apenas em meados do século XIX que aos habitantes de origem portuguesa e açoriana juntaram-se imigrantes alemães à frente de grandes casas comerciais de importação e exportação, definindo uma nova etapa no quadro urbano pioneiro de Itajaí. Articulado às mudanças que se operavam no cenário político e econômico do país, na primeira metade do século XIX, o porto relacionava-se principalmente com Desterro (atual cidade de Florianópolis), a capital da província. Uma nova dinâmica entre a classe mercantil portuária e as áreas próximas se estabelece com a fundação de vários núcleos de colonização européia nos vales do rio Itajaí-Açu (Blumenau, Rio do Sul, Gaspar, etc) e seu afluente, o rio Itajaí-Mirim (Brusque). O porto ainda em sua fase 'natural' passa a servir de escoadouro de uma pequena produção mercantil oriunda da agroindústria colonial, promovendo o desenvolvimento de Itajaí como praça exportadora de mercadorias produzidas nas áreas coloniais e importadora de produtos industrializados para o abastecimento das necessidades regionais (MOREIRA, 2003).

Registros históricos apontam que foi a partir da década de 1920 que os primeiros veranistas provenientes, sobretudo, do Vale do Itajaí onde os núcleos coloniais haviam dado lugar a importantes centros industriais dão início à construção de segundas residências na praia central do atual município de Balneário Camboriú. Corrêa (1985, p.26) afirma que "a partir de 1926 começaram a apontar no centro da praia as primeiras casinhas de veraneio construídas pelos teuto-brasileiros, vindos principalmente de Blumenau".

Assim, a dinâmica sócio-espacial do litoral centro-norte catarinense começa a sofrer alterações significativas, em conseqüência das transformações na conjuntura regional e nacional, bem como na popularização do veraneio que se afirmam 
SANTOS JR., A. dos \& PEREIRA, R.M.F.A. As recentes transformações...

especialmente a partir da década de 1950 e 1960.

Inserido na organização do espaço litorâneo brasileiro desde o século XVI, o litoral catarinense passou, grosso modo, por dois grandes momentos: o primeiro, da colonização até as primeiras décadas do século $\mathrm{XX}$, período em que enquanto a economia brasileira apoiava-se na agroexportação, o Brasil Meridional, e particularmente o litoral catarinense é marcado pela entrada do país na era da industrialização, intensificada após a Revolução de 1930, fato que assinala no plano interno a fase depressiva do $3^{\circ}$ ciclo de Kondratieff. Confirmando a teoria difundida por Rangel de que o Brasil reage positivamente tanto nos períodos de expansão como nos de recessão econômica, na fase depressiva do $3^{\circ}$ ciclo longo (1921-1948) tem início à expansão capitalista moderna (PEREIRA, 2003), que acelera o processo de industrialização do país.

O modelo vigente até então que privilegiava os latifundiários agroexportadores, cuja principal fonte de receita provinha da exportação de gêneros agrícolas, foi substituído por um novo acordo político que atendia aos interesses dos latifundiários ligados ao mercado interno e à nascente classe industrial urbana, desalojando do poder os comerciantes ligados à importação e exportação. Esse processo favoreceu a produção voltada para o mercado interno através de uma política de substituição industrial de importações, responsável por uma reação interna positiva frente ao período depressivo da economia mundial, marcado pela crise de 1929.

Pereira (2003, p.114) ressalta que o "período compreendido de 1930 até meados da década de 1950 é caracterizado pela transição de uma economia agro-exportadora para a urbanoindustrial que acelera a urbanização brasileira". Esse novo modelo econômico, que privilegia a produção industrial, beneficia os núcleos de colonização européia do Vale do Itajaí, onde a pequena produção mercantil dera origem a pólos industriais muito dinâmicos. A conjuntura internacional favorece a emersão das relações capitalistas de produção no país e o surgimento de uma burguesia nas cidades das áreas coloniais, tais como Blumenau e 
SANTOS JR., A. dos \& PEREIRA, R.M.F.A. As recentes transformações...

Brusque, que passa a dispor de recursos e tempo livres para a prática do lazer no litoral, promovendo mudanças nas funções das localidades praianas e alterando, através da balnearização, sua organização sócio-espacial. Este período caracteriza-se pela introdução, por uma elite proveniente das áreas de imigração européia situadas nos vales atlânticos, da prática do veraneio nas praias do litoral catarinense, numa demonstração da força da pequena produção mercantil (MAMIGONIAN, 2000).

Por outro lado, na década de 1940, a aprovação da CLT (Consolidação das Leis Trabalhistas) já regulamentara as condições de trabalho, criando o salário mínimo, reduzindo a jornada laboral para oito horas diárias, concedendo direito à férias e ao descanso remunerado ao trabalhador, que acaba por estender a possibilidade da prática do lazer e do turismo a uma parcela maior da população (REJOWSKI, 2002).

As mudanças estruturais ocorridas na produção se consolidam com o impulso dado à indústria e com a vigência das novas leis trabalhistas que a partir da década de 1950, permitem o acesso da classe média urbana aos meios de comunicação (televisão, revistas semanais, jornais), os quais começam a divulgar o turismo como um sonho de consumo. Esses fatores conjugados à melhoria nos equipamentos turísticos, ampliação dos sistemas de transportes e comunicação, bem como a crescente urbanização propiciaram o desenvolvimento do turismo no Brasil, numa fase marcada por uma nova fase expansiva da economia internacional que tem início no pós-2a Guerra Mundial (1948 - 1973).

A partir da década de 1960, com a massificação do veraneio e do turismo, ocorre um intenso processo de expansão urbana e de especulação imobiliária no litoral catarinense, provocando um novo ritmo de crescimento, dinamizado pelo setor da construção civil.

Neste contexto, a praia de Camboriú começa a receber veranistas e turistas em número crescente, especialmente nos meses de dezembro, janeiro e fevereiro consolidando-se como uma estação de veraneio, o que acaba levando à emancipação política do Balneário Camboriú, que, em 1964, se desmembra do município 
SANTOS JR., A. dos \& PEREIRA, R.M.F.A. As recentes transformações...

de Camboriú. As ações implantadas a partir da sua emancipação favoreceram o surgimento de uma infraestrutura receptiva que acabou por destacá-lo, como um dos principais destinos turísticos do litoral catarinense e do estado de Santa Catarina.

$\mathrm{Na}$ década de 1970, o desenvolvimento das atividades turísticas no Balneário Camboriú é impulsionado por novas tendências na conjuntura econômica nacional marcada pelo período do "Milagre Brasileiro" (1968 - 73), quando o Produto Interno Bruto alcançou a taxa média de $11,5 \%$ ao ano e o setor industrial, em particular, com taxas superiores a 13\% (ROCHA, 2004), em razão da coincidência entre a fase expansiva do $4^{\circ}$ ciclo longo e a fase ascendente do ciclo de Juglar. Cabe lembrar que o ciclo longo é definido pela conjuntura econômica internacional, enquanto o ciclo médio ou juglariano é determinado pela conjuntura da economia nacional, com duração de aproximadamente um decênio, sendo os primeiros lustros de cada década são depressivos, enquanto as fases ascendentes ocorrem nos segundos lustros (RANGEL, 2005). Essa coincidência desencadeou um forte crescimento urbano, promovido por ações efetivadas pelo Estado, em todas as instâncias. Um marco delas é representado pela construção da BR-101 (1953-1971), uma rodovia federal que corta o litoral catarinense no sentido norte-sul, integrando as comunidades litorâneas catarinenses às novas formas de produção - industrialização e circulação econômica nacional.

A forte presença do Estado no comando dos processos ditos modernizantes da economia brasileira provoca transformações sócio-espaciais, viabilizando, por exemplo, a urbanização dos balneários, traduzindo no território catarinense as orientações de uma lógica nacional em curso, expressa pela nova conjuntura política e econômicas. (SILVA, 1997).

Inicialmente, o capital investido no litoral centro-norte catarinense foi prioritariamente direcionado para Balneário Camboriú, provocando grandes mudanças na organização do espaço e promovendo uma concentração demográfica na faixa correspondente à praia central. Posteriormente, os investimentos 
SANTOS JR., A. dos \& PEREIRA, R.M.F.A. As recentes transformações...

foram disseminados para as praias dos municípios litorâneos vizinhos (especialmente Itapema, Porto Belo, Bombinhas, Piçarras, Penha, Barra Velha e Itajaí).

É importante ressaltar que a depressão da economia internacional iniciada em 1973, com a crise do petróleo, se estende pela década de 1980 quando, no Brasil, se esgota o período militar afetado também pela fase recessiva do ciclo médio. A conjuntura desfavorável, tanto no plano externo como no interno, faz o país atravessar um período de profunda recessão que ficou conhecido como a "década perdida". No entanto, o fluxo de turistas argentinos favorecido pela política cambial do país vizinho permitiu investimentos que impulsionaram os negócios, sobretudo imobiliários, no Balneário Camboriú. Os empresários regionais, por sua vez, percebem as vantagens de aplicar o capital no setor, como reserva de valor.

No caso da Praia Brava, cuja área permanecia até então à margem do processo de expansão da orla litorânea dessa região, é somente no final da década de 1990 que tem início um acelerado processo de transformações sócio-espaciais, que a tornam um balneário satélite de Balneário Camboriú, especialmente em razão da relativa conservação de suas características naturais.

\section{O turismo e as transformações sócio-espaciais}

O conceito de formação sócio-espacial considera as formas espaciais como resultantes da dialética entre sociedade e natureza, ditada pela evolução das forças produtivas e das relações sociais dominantes em cada período histórico. Assim é que somente no final do século XX, quando as relações de produção atingem um novo patamar em nosso país, é que a Praia Brava começa a passar por um processo de transformação, decorrente da apropriação daquela área para fins residenciais e turísticos.

Constata-se, pois, que o espaço caracteriza-se, simultaneamente, como condição, meio e produto do processo de reprodução da sociedade, o que é ainda mais verdadeiro em uma economia globalizada, pois 
SANTOS JR., A. dos \& PEREIRA, R.M.F.A. As recentes transformações...

[...] o espaço geográfico ganha novos contornos, novas características, novas definições. E, também, uma nova importância, porque a eficácia das ações está estreitamente relacionada com a sua localização. Os atores mais poderosos se reservam os melhores pedaços do território e deixam o resto para os outros (SANTOS, 2000, p.79).

Se por um lado a idéia de globalização parece contrair o espaço e o tempo, por outro não pode induzir à equivocada conclusão de que o espaço perdeu importância, visto que a globalização, ao contrário, levou à reasserção das tendências de aglomeração em diferentes partes do mundo (SCOTT, 2000, p.47). O uso indiscriminado dessa variável explicativa, por sua vez, pode vir a aprisionar o pesquisador, impedindo a visão da dinâmica interna (nacional e regional), responsável pelas transformações em qualquer organização sócio-espacial. Ou seja, o desenvolvimento ocorre de forma concentrada e não difusa, contrariando a vertente globalista que acreditava na homogeneização do espaço.

Interesses conflitantes sobre o uso de um mesmo espaço geram disputas territoriais, nas quais visões de mundo antagônicas manifestam-se. O paraíso dos ambientalistas representa, para os incorporadores o desperdício de uma área vocacionada para empreendimentos altamente lucrativos, um filão imobiliário. Estas disputas acontecem quando as leis do mercado transformam a paisagem em produto de consumo, levando a um processo de transformação sócio-espacial dos lugares. Cumprindo o ciclo do produto, a atividade turística de elite, inicialmente, e de massa, em um segundo momento, apropria-se de porções do território, gerando novas espacialidades (LUCHIARI, 2004). Esse processo tem sido especialmente intenso e acelerado no litoral de Santa Catarina, e de modo particular, na região da foz do rio Itajaí-Açu, onde se encontra se localiza o Balneário Camboriú. É dentro deste panorama que está inserida a localidade em estudo, o bairro da Praia Brava, que das primeiras décadas do século XX até início da década de 1990, permaneceu à margem do processo de balnearização que ocorria em vários municípios litorâneos da foz do rio 
SANTOS JR., A. dos \& PEREIRA, R.M.F.A. As recentes transformações... Itajaí-Açu, impulsionado pela construção de segundas residências para veraneio e pelo aumento do fluxo de turistas.

\section{O bairro da Praia Brava}

Na faixa litorânea de Santa Catarina, na porção centro-norte, entre os municípios de Luiz Alves e Bombinhas, está localizada a micro-região da foz do rio Itajaí-Açu. O bairro Praia Brava, situado entre os municípios de Itajaí e Balneário Camboriú (figura 1), recebeu, no século XIX, seus primeiros moradores que desenvolviam atividades mais ligadas à terra do que ao mar.

\section{FIGURA 1: Localização do bairro Praia Brava}

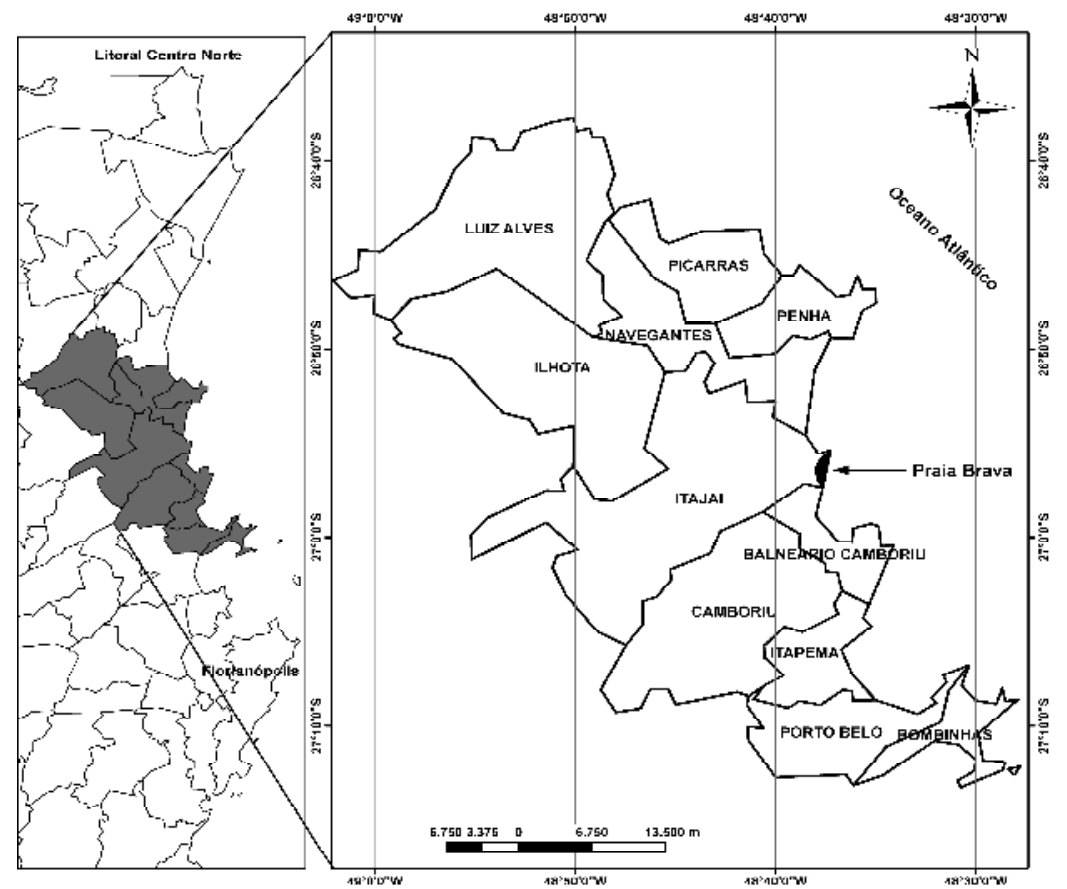

Fonte: Laboratório de Geoprocessamento - CTTMar/Univali, 2007. 
SANTOS JR., A. dos \& PEREIRA, R.M.F.A. As recentes transformações...

$\mathrm{Na}$ Praia Brava não se registra o padrão histórico de ocupação na frente da praia por ranchos de pesca que são transformados, posteriormente, em residências, como aconteceu com as demais praias vizinhas (figura 2). Isto se deve à ausência de uma comunidade pesqueira efetiva (que vivesse somente da pesca). Assim sendo, os recuos foram ocupados diretamente pelos estabelecimentos comerciais (bares), que se multiplicaram nos últimos anos (SOUZA JR, 1997).

\section{FIGURA 2: Vista parcial do bairro Praia Brava}

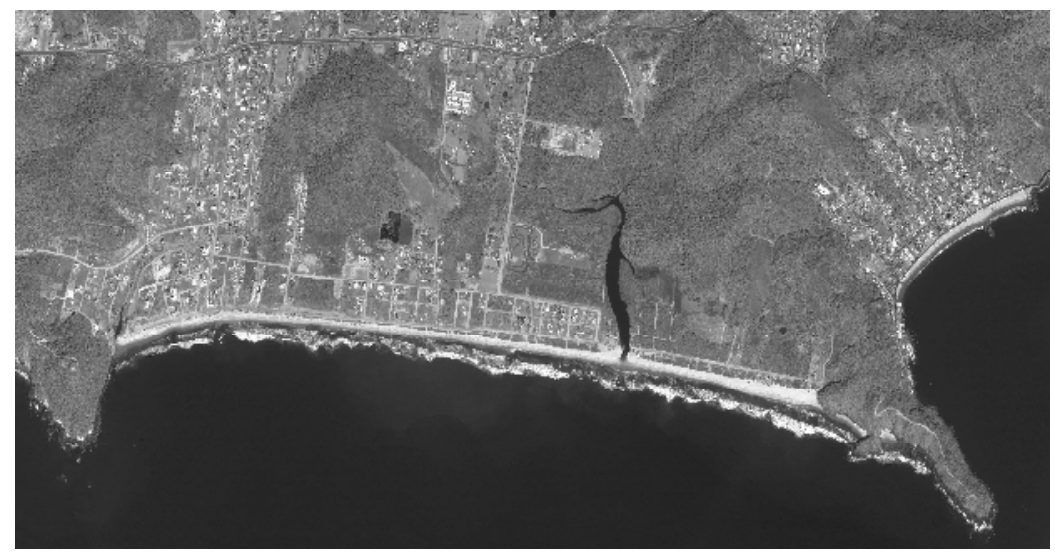

Fonte: Laboratório de Geoprocessamento - CTTMar/Univali, 2007.

A antiga Estrada Geral Itajaí - Florianópolis que fazia a ligação do centro regional (Itajaí), com a capital do estado catarinense (Florianópolis), deu origem à comunidade da Praia Brava, cortando o bairro e dividindo-o em áreas distintas. $\mathrm{Na}$ atualidade, esta rodovia consiste no principal corredor de ligação viária entre os municípios de Itajaí e Balneário Camboriú, apresentando elementos de conurbação, pois ao longo desta via houve um adensamento da ocupação do espaço, em conseqüência da construção de residências e da instalação de estabelecimentos comerciais, o que gera um fluxo ininterrupto decorrente da relação 
SANTOS JR., A. dos \& PEREIRA, R.M.F.A. As recentes transformações...

de interdependência e da integração entre essas duas cidades nas diferentes áreas de trabalho, lazer e diversão.

As perspectivas do desenvolvimento geradas pelo crescimento urbano e de setor turístico na orla litorânea catarinense logo atraíram a atenção de capitalistas e políticos para as terras consideradas devolutas localizadas ao longo do litoral para futura especulação imobiliária e turística. No caso da Praia Brava, esse processo teve início com Francisco Canziani, deputado estadual, construtor e agente imobiliário. Através de argumentos jurídicos, Canziani requereu várias glebas de terras localizadas às margens da Estrada Geral Itajaí - Florianópolis (futura Rodovia Osvaldo Reis), envolvendo, ao todo, 34 propriedades de tamanhos distintos, totalizando $6.580 .130,80 \mathrm{~m}^{2}$.

Durante a década de 1950 e nas seguintes, outras glebas de terras, localizadas frente ao mar também foram requeridas por pessoas da alta sociedade itajaiense e da região e transformadas em loteamentos.

Ressalte-se que os loteamentos implantados a partir da década de 1950 até final da década de 1970, apesar de comercializados, não foram ocupados por segundas residências, permanecendo com poucos moradores fixos.

É somente a partir do início da década de 1980, com a implantação do loteamento "Praia dos Amores", pelos sóciosproprietários da Companhia Hering, sediada na cidade de Blumenau, que as segundas residências começam a transformar o espaço litorâneo da Praia Brava de forma mais intensa. O processo de ocupação urbana se intensifica a partir desse loteamento, com aterros das áreas mais baixas onde havia afluentes secundários do sistema de drenagem do ribeirão Ariribá e a retificação do mesmo. Nessa área ocorre um intenso processo de ocupação, facilitado pelo acesso pavimentado ligando a praia à rodovia Osvaldo Reis (Av. Carlos Drumond de Andrade), além de outro acesso direto ao Balneário Camboriú pela estrada da Rainha, reurbanizada, com alargamento, pista dupla e pavimentação asfáltica, interligando a praia central do Balneário Camboriú à Praia Brava. $\mathrm{O}$ crescimento 
SANTOS JR., A. dos \& PEREIRA, R.M.F.A. As recentes transformações...

da urbanização nesta área é visível, registrando-se já um início de verticalização das construções em resposta às pressões por falta de espaço e pela valorização imobiliária

O bairro Praia Brava apesar de sua pequena extensão, apresenta realidades distintas. As diferentes características na configuração espacial decorrem da variedade dos elementos naturais e humanos existentes na área. Em sua porção central, contígua ao loteamento "Praia dos Amores", localizado na parte sul, registra-se um processo de urbanização crescente, embora ainda se encontrem "ilhas" de vegetação de restinga e remanescentes da Mata Atlântica. Todavia, as segundas residências já estão presentes em vários locais e a abertura de hotéis e bares em frente à praia sinalizam mudanças recentes na sua organização espacial.

$\mathrm{Na}$ porção norte, conhecida como Canto do Morcego, o limite natural é a Lagoa do Cassino, que separa o norte do restante da praia. Aqui, os ecossistemas costeiros representados por dunas, manguezais, restingas e remanescentes da Mata Atlântica se encontram em bom estado de conservação. $\mathrm{O}$ acesso de veículos a esta parte da Praia Brava é feito somente através do bairro de Cabeçudas (Itajaí) por uma rodovia situada entre morros. Entretanto, já existem vários projetos imobiliários sendo analisados pelo poder público para esta área (figura 3), tendo sido instalado aí equipamentos turísticos voltados para shows noturnos (Warung e Kiwi). O trânsito intenso, entretanto, já vem provocando alterações no meio natural, devido, sobretudo, ao estacionamento irregular de automóveis sobre a vegetação de dunas da planície costeira. Cabe ressaltar que esta porção da Praia Brava ainda não possui rede de abastecimento de água e energia elétrica o que, até o momento, representa uma restrição à ocupação.

Os interesses conflitantes quanto ao uso do território da Praia Brava têm gerado processos, abaixo assinados, comunidades no orkut e outros recursos os quais estão em andamento, razão pela qual a questão ainda não pode ser considerada definitiva. Entretanto, a disparidade entre as forças envolvidas permite prever um desfecho desfavorável aos ambientalistas. De um lado a 
SANTOS JR., A. dos \& PEREIRA, R.M.F.A. As recentes transformações...

natureza é vista como patrimônio coletivo e, portanto, como direito difuso assegurado. De outro, a turistificação dos lugares, que traz a implacável lógica do mercado, transformando a paisagem em produto a ser vorazmente consumido.

\section{FIGURA 3: Condomínio turístico - Canto da Brava}

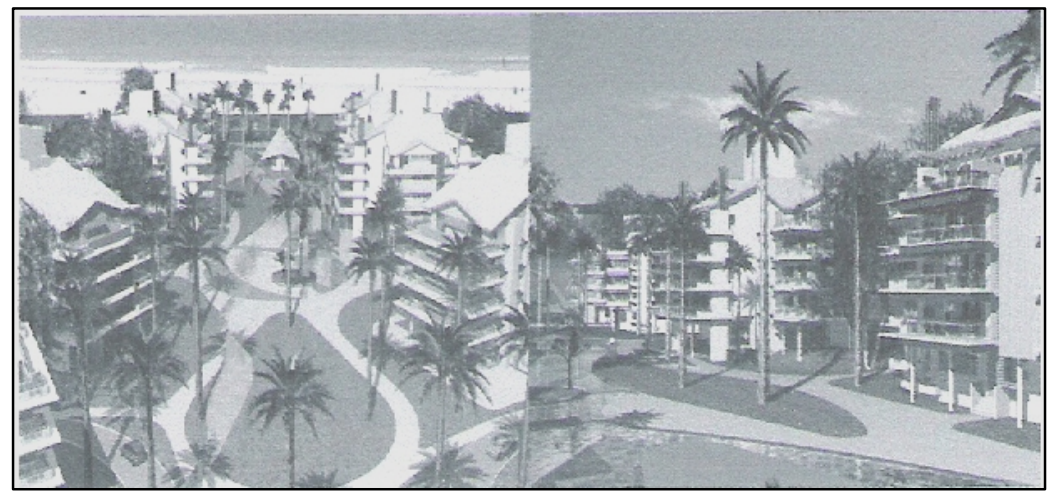

Fonte: http//www.des.floripa.com.br/condomínio/HTML

Esses projetos de resorts e condomínios estão sendo discutidos pela comunidade, gerando, por um lado, revolta nos defensores da conservação da praia em seu estado atual e, de outro, grupos imobiliários ávidos por áreas com vista para o mar (figura 4).

Desde meados da década de 1990, vem se registrando na Praia Brava uma intensificação da construção civil relacionada tanto à edificação de residências para moradores fixos, como de segundas residências para veraneio. Esse momento coincide com o estabelecimento de professores e estudantes universitários que passam a residir na Praia Brava, chamando a atenção para os problemas ambientais ali existentes. A partir de então várias organizações não-governamentais são constituídas e os conflitos de interesses entre os atores sociais se tornam mais evidentes: 1) os preservacionistas defendem a realização de estudos para o planejamento sustentável, visando à manutenção das características 
SANTOS JR., A. dos \& PEREIRA, R.M.F.A. As recentes transformações...

ambientais e paisagísticas do local; 2) setores ligados ao ramo imobiliário e a construção civil, visam, sobretudo, a maximização do lucro; 3) os moradores locais têm a expectativa da geração de emprego com o desenvolvimento do turismo; 4) os turistas e os veranistas clamam por uma melhor infraestrutura e 5) o poder público que tem interesse na arrecadação de impostos.

\section{FIGURA 4: Condomínio Brava Beach Internacional}

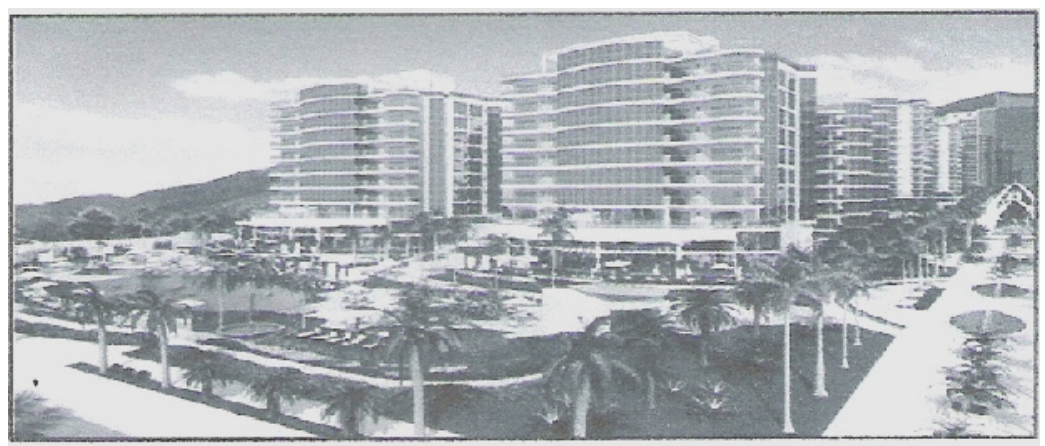

Fonte: www.bravabeachvendas.com.br

Diante dos conflitos, o poder público formalizou um plano de urbanização para a área que, entretanto, tem-se mostrado ineficiente quanto à elaboração de uma política de planejamento urbano que harmonize os valores não materiais relacionados diretamente à paisagem e os interesses econômicos de diferentes grupos.

A organização espacial da Praia Brava retrata as pressões sócioeconômicas atuantes nessa área, já que, com o crescimento da população residente e visitante, sua configuração original foi modificada pela intensificação das construções e pelo início da verticalização nas áreas próximas à orla marítima. Em termos históricos, o espaço urbano, que começou a se delinear a partir da rodovia Osvaldo Reis, expandiu-se aceleradamente nos últimos anos para a faixa litorânea, que se tornou alvo da cobiça de grupos interessados no lançamento de grandes empreendimentos imobiliários. 
SANTOS JR., A. dos \& PEREIRA, R.M.F.A. As recentes transformações...

\section{Considerações finais}

As transformações sócio-espaciais, no bairro da Praia Brava decorrem da transição das atividades tradicionais (agricultura e pesca) para a atividade turística, devido à expansão urbana, à melhoria na malha viária que interliga os municípios de Itajaí e Balneário Camboriú, à sua atratividade natural e à expansão do próprio desenvolvimento turístico do Balneário Camboriú.

Durante várias décadas este bairro praiano de Itajaí, permaneceu à margem do processo de balnearização que ocorria em vários municípios litorâneos da foz do rio Itajaí-Açu, impulsionados pela construção de segundas residências, construídas por uma burguesia emergente localizada no Vale do Itajaí, em particular, de Blumenau e Brusque.

Entretanto, a partir da década de 1990 essa área começa a passar por rápidas transformações sócio-espaciais. Esta nova organização sócio-espacial foi impulsionada, principalmente, pela melhoria no sistema viário e pelo desenvolvimento do turismo nos municípios vizinhos.

A partir dos anos iniciais do século XXI, com a expansão urbana dos municípios de Balneário Camboriú e de Itajaí, provocadas pelo crescimento da população e pelo desenvolvimento das atividades ligadas ao turismo, o bairro Praia Brava vem perdendo suas características originais, induzidas especialmente pelo aumento de moradores oriundos de diversas localidades. Essas alterações resultaram, sobretudo, numa especulação imobiliária, que num curto período de tempo transformou o local em uma área bastante valorizada.

Em conseqüência, percebem-se conflitos latentes decorrentes da divergência de interesses entre os vários grupos sociais que moram neste bairro. As discussões envolvendo entidades ambientalistas, Ministério Público e órgãos ambientalistas de um lado e entidades empresariais e políticos de outro, permitem compreender os interesses conflitantes entre a conservação da natureza e os interesses econômicos. 
SANTOS JR., A. dos \& PEREIRA, R.M.F.A. As recentes transformações...

O quadro descrito mostra que a Praia Brava sofre um acelerado processo de transformação sócio-espacial. As mesmas características morfológicas que fazem com que este território tenha atributos ecológicos privilegiados fazem dele objeto de cobiça dos empreendedores imobiliários e turísticos, gerando relações contraditórias e antagônicas próprias do sistema capitalista, entre seus moradores e freqüentadores.

\section{Referências bibliográficas}

CHOLLEY, A. Observações sobre alguns pontos de vista geográficos. In: Boletim Geográfico ano XXII, n 179 mar/abr CNG/IBGE, 1964.

CORRÊA, I. de B. História de duas cidades: Camboriú e Balneário Camboriú. Ed. do Autor, 1985.

LUCHIARI, M. T. D. P. Urbanização Turística - um novo nexo entre o lugar e o mundo. In: BRUNHS, H. et all. (Org.). Olhares Contemporâneos sobre o Turismo. $3^{\text {a }}$ ed. Campinas: Papirus, 2004.

MAMIGONIAN, A. Teorias sobre a Industrialização Brasileira. Cadernos Geográficos - Publicação do Departamento de geociências - CFH/UFSC, Florianópolis: 2000.

MOREIRA, M.T. A Formação do Capital Mercantil e Industrial em Itajaí(SC): uma industrialização incompleta. 2003, 121 f. Dissertação (Mestrado em Geografia) - Centro de Filosofia e Ciências Humanas, UFSC, Florianópolis, 2003.

RANGEL. I. Obras Reunidas. Rio de Janeiro: Contraponto, 2005.

PEREIRA, R.M.F.A. Formação sócio-espacial do litoral de Santa Catarina (Brasil): gênese e transformações recentes. In: Geosul, v. 18, n. 35. Florianópolis: EDUFSC, 2003. p. $99-129$.

REJOWSKI. M. (Org.). Turismo no percurso do tempo. São Paulo: Aleph, 2002. 
SANTOS JR., A. dos \& PEREIRA, R.M.F.A. As recentes transformações...

ROCHA. I. de O. A inserção internacional das indústrias catarinenses. São Paulo, 2004. (Projeto de tese - relatório de qualificação -Departamento de Geografia - USP).

SANTOS, M. Espaço e Sociedade. 2a ed. São Paulo: Vozes, 1982.

- A natureza do espaço: Técnica e tempo, razão e emoção. $4^{\mathrm{a}}$ ed. São Paulo: EDUSP, 2009. (Coleção Milton Santos).

. Por uma outra globalização: do pensamento único à consciência universal. Rio de Janeiro: Record, 2000.

SCOTT, J. A. Regions and the world economy: the coming shape of global production, competition and political order. New York: Oxford University Press, 2000.

SILVA. C.M. et al. A (re)produção do espaço litorâneo catarinense. In: Anais do Congresso de História e Geografia de Santa Catarina. Florianópolis: CAPES/MEC, 1997. p. 468-479.

SOUZA JR. S. de. Evolução e tendências de crescimento da paisagem urbana nos balneários do litoral centro-norte catarinense. Itajaí 1997. (Relatório de pesquisa).

UNIVERSIDADE DO VALE DO ITAJAÍ, Laboratório de Geoprocessamento - CTTMar/Univali, 2007.

http://www.dcs.floripa.com.br/condominios.html> acesso em: 18 set. 2009.

http:// www.bravabeachvendas.com.br> acesso em 19 set. 2009.

http://tetetrips.blogspot.com/2007/10/bela-geografia-de-santacatarina.html>acesso em 20 abr. 2008. 